\title{
Perceptions of Construction Work: Views to Consider to Improve Employee Recruitment and
}

\section{Retention}

Katherine Welfare, Ph.D. ${ }^{1}$; Fred Sherratt, Ph.D., M.ASCE ${ }^{2}$; and Matthew Hallowell, Ph.D., M.ASCE ${ }^{3}$

${ }^{1}$ Research Faculty and Associate Director of Construction Safety Research Alliance, Dept. of Civil, Environmental, and Architectural Engineering, Univ. of Colorado Boulder, 1111 Engineering Dr., UCB 428, Boulder, CO 80309 (corresponding author). ORCID:

https://orcid.org/0000-0002-2609-942X. Email: dewlanek@colorado.edu

${ }^{2}$ Associate Professor in Construction Management, Dept. of Engineering and the Built Environment, Anglia Ruskin Univ., Bishop Hall Ln., Chelmsford CM1 1SQ, UK. ORCID: https://orcid.org/0000-0002-3255-7562. Email: fred.sherratt@aru.ac.uk

${ }^{3}$ President Teaching Scholar and Beavers Endowed Professor of Construction Engineering, Dept. of Civil, Environmental, and Architectural Engineering, Univ. of Colorado at Boulder, 1111 Engineering Dr., UCB 428, Boulder, CO 80302. Email: matthew.hallowell@colorado.edu

\begin{abstract}
With increasing demands for new infrastructure and a decreased availability of skilled construction craft workers, the need to recruit and retain workers is becoming critical. It is important to understand the preferences of workers and, consequentially, ensure that positive attributes of the job are preserved and negative attributes are mitigated in practice. To better understand the preferences of construction workers, 222 interviews were conducted with workers on active commercial construction sites in Colorado. Workers were asked simple, open- ended questions about their jobs and work preferences using a social constructionist approach. The results indicate that workers most enjoy seeing tangible results, social interaction with coworkers, problem-solving, challenging and diverse work tasks, and working with their hands. Conversely, negative attributes were work pressure, indirect communication, mandates from upper management, dangerous work, and a feeling of indifference perceived by their coworkers. These results improve understandings of the fundamental reasons why construction workers are attracted to their profession.
\end{abstract}




\section{Introduction}

The construction industry is currently suffering from skilled labor shortages. While this is in part attributed to the perceived long-term trend of recruitment problems in the construction industry and the cyclic nature of the field (a result of the sensitivity to the underlying economic cycle) (Karimi et al. 2016), other factors are also influential. There are two major contributors to this low number of skilled craft workers. Firstly, an increasing number of veteran workers are leaving the industry due to retirement (CIR 2017). Secondly, there is a lack of new workers entering the industry (Shelar 2013; Makhene and Thwala 2009). This may be due to the nature of the work itself; the success of any construction project is largely due to challenging, laborious, and often dangerous tasks manually undertaken by construction workers, and unlike other industries, construction is transient, dynamic, and associated with both long and short-term uncertainty. Perhaps, unsurprisingly, this situation has resulted in increasing labor shortages, especially for skilled craft workers, and efforts to fill this gap are becoming increasingly urgent.

While there are solutions available to the skilled labor shortage problem, such as working to retain current craft workers, attracting new workers, and creating different management approaches, continued efforts to close this gap remain critical. Recruitment and retention strategies are becoming more aggressive, but the industry image has remained stagnant for some time. Some unique recruitment and retention strategies include increased wages, over- seas recruitment, reformatting training requirements, increasing the Hispanic workforce, and implementing a multiskilled workforce (Lobo and Wilkinson 2008; Goodrum 2004; Haas et al. 2001). However, rather than focusing on what the industry can offer to prospective job seekers, it may be beneficial to understand the positive attributes of the industry from those currently satisfied working within it.

Given the pressing need for workforce enhancement, the industry may wish to consider what attributes of the work are attractive and those that are unattractive, especially as such preferences apply to younger workers. As noted by Beer et al. (1985) and Walton (1985), human resources are the most important asset for achieving organizational success in project-based industries. Human resources add value through adaptability, creativity, flexibility, and problem-solving skills (Druker et 
al. 1996). Thus, employers should seek to understand work preferences better and evaluate the impact of prioritizing short-term drivers like work pressure on motivation, satisfaction, and, ultimately, longterm financial sustainability.

Therefore, this study sought to understand how construction- worker perspectives of their jobs can affect the workforce positively, providing insights for beneficial recruitment and retention policies and initiatives in practice. This research builds upon the existing knowledge of work preferences as studied in social sciences by examining its generalizability to construction. Specifically, we seek to understand what attributes of construction work are attractive, neutral, and unattractive to construction workers across differing demographics. Such knowledge can enable human-centered decisions that positively impact construction workers' well-being, safety, and performance (Edmonds 2016).

\section{Background and Literature Review}

The body of literature on work preferences is fragmented and dispersed across industries, and there has yet to be a comprehensive study of work preferences in construction. With the objective of identifying the fundamental preferences of construction work independent of the sector, trade, or discipline, a thorough review of the literature of work preferences across industries was completed.

\section{Work Attributes}

It is broadly understood that people like their jobs for many different reasons, including the following: the enjoyment and sense of challenge of the work; social interaction; the ability to be creative; participating in satisfying and engaging work tasks; recognition of work-life balance; a sense of belonging; and engagement through inspiration, commitment, and fascination (Amabile 1997; Cohen and Prusak 2001). Other researchers have drawn similar findings that vary depending on the research design and context. For example, Turner and Lawrence (1965) found six attributes that define work preferences: variety, autonomy, required interaction, optional interaction, knowledge and skills required, and responsibility. More recently, Csikszentmihalyi (2000) found eight attributes: enjoyment of the application of the acquired skill; motions and patterns of the activity; development of personal skills, friendship, and companionship; extrinsic competition by measuring oneself against peers; 
intrinsic competition by measuring oneself against internal ideals; emotional release; prestige; and glamour. Finally, Seijts and Crim (2006) found that workers prefer connecting with employees, clear vision from leadership, direct expectations and feedback, praise and recognition for strong performance, feeling empowered, autonomy, collaboration with a team, high ethical standards, and credible reputation and confidence.

The dispersed literature in this domain is summarized in Table 1. This table outlines the various work attributes that appeared most often throughout literature across all industries. While there is no specific literature on work attributes in construction, there is a significant amount of research on this topic in other industries. The eight most influential references (as measured by citations) were included in this table. There is some overlap in the findings, but there is not a clear and prioritized set of attributes that can be adapted for construction. This literature represents the overarching themes that were later used by the authors to code, analyze, and compare construction interview data for validation.

Although there are considerable fragmentation and dispersion of the literature on work preferences, Herzberg et al. (1959) theorized that job preferences could be simply modeled using the motivatorhygiene theory. The premise is that there are five attributes of a job that produce either satisfaction or dissatisfaction (motivators):

(1) achievement, (2) recognition, (3) pleasure of the typical work activities, (4) responsibility, and (5) advancement. Alternatively, the factors of dissatisfaction (hygienes) are caused by (1) policy and administration, (2) supervision, (3) pay, (4) relationships among coworkers, and (5) work conditions. Subsequent studies have supported this model and sought to define these factors in greater detail (e.g., Bowen 1980; Padilla-Velez 1993).

A vast amount of literature exists striving to determine what people fundamentally need to be satisfied at work. The theoretical background to this area of research is in the majority based on the original findings of Maslow's hierarchy of needs and Herzberg's two-factor theory. Many organizations follow these theoretical frameworks to build programs to improve job satisfaction but frequently 
without input from the workers. More specific and detailed literature around satisfaction again references a number of factors, including promotion, establishment, size, work hours, income, and an individual's unique perceptions (Locke 1969; Kosteas 2010, p.176). More interestingly, Locke argues that the essential point from his research on job satisfaction is that the causes of job satisfaction are not only due to the actual worker or just the job but actually the relationships between the two.

The preferences shown in Table 1 represent the foundational knowledge for this study, which was used as a foundational framework for the coding schema used in the empirical work.

[Table 1 at end of document]

Although work preferences have been studied broadly, construction is arguably different because of the transient, dynamic, and dangerous nature of the work. Therefore, it is important to understand the extent to which general preferences extend to construction work and what preferences uniquely apply to construction. There is a large gap in research related to work preferences as perceived by construction workers. The application of a social constructionist approach and the use of qualitative data in this study enables the perceptions of the workers to be examined in-depth and without preprescribed categorizations or assumptions, thereby providing greater insights and understandings of the preferences of the construction workforce.

\section{Research Questions}

The aim of this study was to identify and document the work preferences of construction workers. Simply and colloquially, this study examines what workers like and dislike about their jobs. To achieve this aim, the following research questions were addressed:

- What attributes for construction work are generally the most desirable?

- What attributes for construction work are generally the least desirable?

- How do the findings for construction compare to general work preferences found in the existing literature? 
It is the goal that the findings from this research will encourage deeper consideration of worker perceptions and create a foundation for changes in recruitment and retention strategies in construction.

\section{Research Approach}

\section{Methodology}

The objective of this study was to identify the fundamental preferences of construction work that are independent of sector, trade, or discipline. Importantly, we aimed to collect data directly from workers without asking leading questions or using a survey that would bias responses to preconceptions. Specifically, the study in- volved (1) a thorough review of literature in work preferences across industries; and (2) open-ended interviews with 222 construction workers and subsequent analysis using both content and discourse analysis. An iterative approach was used to objectively code and subjectively explore the data using both content analysis and discourse analysis. This mixed methodological approach was thus able to reveal a nuanced, detailed, and thorough understanding of work preferences.

In order to better understand preferred work attributes in construction, and the extent to which findings from other industries and applications generalize to construction, a social constructionist approach was used. Grounded in a relativist ontological position, social constructionism is an epistemology that posits that individuals constantly socially construct their own versions and understandings of the world (Burr 2003), and different perspectives coalesce around dominant shared understandings of reality. Social constructionism has been essential in the development of theories related to culture and society (Eggert et al. 2014) and is frequently used within the social sciences to provide comprehensive insight into everyday life within specific contexts and situations (Taylor 2001). Therefore, the approach is highly suited to exploring the phenomenon of what workers like and dislike about their jobs as it supports variations in the findings and provides insights into the lived realities of the workers themselves. 
Through social constructionism, language becomes the tool through which different realities and truths of social life are con- structed in the form of discourses (Potter and Hepburn 2008). Participants tell their truths of how they see the world at that particular time, which can include variation and even contradictions. This reflects the messy nature of the world, as people construct and reconstruct it to make sense to them and which combine in the wider social space to form discourses. Paltridge (2013, p. 2) claimed that "discourse is one of the most significant concepts of contemporary thinking in the humanities and social sciences as it concerns the way language mediates and shapes our interactions with each other and with the social, political, and cultural formations of our society." Discourse analysis establishes the relationship between language and context by examining the patterns of language and considering the relationship between words and the cultural contexts in which they are used. Such analysis enables the researchers to consider how views of the world vary and examines the relationships between participants, being able to draw conclusions from verbal responses (Jørgensen and Phillips 2011). Although the epistemological position of social constructionism dictates that findings cannot be generalized in the traditional sense, they can still find fit and resonance with those who experience this specific context on a daily basis and thus build the foundation for recommendations of different practices and interventions to produce change and solve problems (Gergen and Gergen 2004). The reliability of the process is assured through the explication of the methods of data collection and analysis, as well as an external comparison among responses and an internal comparison within responses to establish dominant patterns (Taylor 2001; Burr 2003). Although a social constructionist approach cannot look to traditional positivistic measures of validity, such as controlled testing environments, the external and ecological validity of this data is high as it was collected from the target population, with demo- graphical variability purposively captured within the sample and a saturation of the findings achieved within the data collected (Kumar 2005). Whether the participants were speaking freely, i.e., telling the truth, is an interesting consideration for validity in this study. A social constructionist approach does not look for the truth; rather, it explores the truths of both individuals and the wider society through the patterns found in the ways things are discussed. In effect, the question of is this the truth? becomes moot. Instead, truths, as constructed by these participants, are un- packed and illuminated through the discourse analysis undertaken, and it is these 
discourses, rather than the truth, that are able to reveal the shared understandings that surround construction work itself.

Therefore, although there is a level of subjectivity with this approach, and indeed is philosophically inevitable in a pure social constructionist approach, this was mitigated in this study by combining content analysis and discourse analysis to provide further assurances of validity within the dataset. Drawing on both methods of analysis further supports the reduction of the bias through within-method triangulation (Harbers and Neerincx 2014). Overall, the combination of a systematic literature review, discourse analysis, and content analysis used to unpack the complexities and inconsistencies that exist among more than two hundred construction workers in Colorado provides a robust empirical approach to answer the research questions.

\section{Participants and Setting}

In this study, a total of 222 construction workers participated in the interviews. All interviews were conducted by one researcher across 15 commercial construction sites in Colorado. Per the human subject protocol, participation was strictly voluntary, the anonymity of each participant was guaranteed, and the results were not shared with the employer, even in aggregate form. Sites were selected based on the project type, size, location, and accessibility and were active, commercial construction sites, ranging from hospitals to multifamily to academic. All sites were located within the Denver metropolitan area. Workers across many construction trades were selected, such as those in general contracting, roofing, mechanical, electrical, fire protection, glazing, painting, millwork, drywall, plumbing, elevator, steel, masonry, concrete, and other finish or specialty trades, and no office personnel or upper management were included. Although there is a limited geographical representation, there is high diversity in the trades included. The demographics of the sample closely resembled the demographics of the construction industry in the United States (Bureau of Labor Statistics 2019). The majority (98\%) of the subjects were male and $2 \%$ female, while $73 \%$ were Caucasian, and $27 \%$ were of Hispanic or Latino descent. Table 2 outlines the experience of the participants.

[Table 2 at end of document] 


\section{Interview Questions}

Interviews formed the method of data collection. As predefined surveys or structured interview templates based upon prior beliefs had the potential to lead the participants and be fraught with confirmatory bias, open-ended questions were asked, and participants were given the freedom to direct the conversations, which was undertaken in a one-on-one setting while out in the field on a construction site. To stimulate conversation and build rapport with the interviewer, workers were first asked to describe their jobs simply. Then, more direct questions were asked about their preferences of work. The specific questions were as follows:

- Tell me about your job.

- What do you do here, and how long have you worked here?

- Have you always done this type of work? If not, what did you do before?

- Why did you choose construction?

- What do you enjoy most about your job, if anything?

- What do you dislike most about your job, if anything?

- Are there any changes you think could or should be made in the workplace?

- Do you think your coworkers feel the same overall about their jobs and the workplace?

The sequencing of these questions both stimulated the conversation while still enabling the workers to lead and develop it on their own terms. Although these prompts were used as a guide, there were circumstances in which variations of questions were asked, questions were omitted, or questions were added based on the natural direction of the conversation. While a framework of the preceding questions was used to focus the conversation on work preferences, the goal was for the conversation to be led by the respondent and to capture the constructions of their preferences in context. This questioning style leads to a comfortable conversation that allows discourse to emerge naturally. Importantly, all interviews were conducted in the field where workers were engaged in construction activities to promote ecological validity and to encourage specificity in responses (e.g., providing 
specific examples). Each conversation was audio recorded with the express permissions of the workers and the employers. Once the interviews were complete, each interview was transcribed verbatim and coded using a digital coding software (NVivo 12 Pro) for further analysis.

\section{Method of Data Analysis}

The approach used in this study meant the coding and analytical process looked not only at what was said by the participants through content analysis but also how workers talked about their jobs through the more nuanced approach of the discourse analysis. A discourse analysis is able to reveal the complexities, consistencies, and inconsistencies from the ways in which workers speak about their job preferences (Wetherell and Potter 1988; Burck 2005). During the analysis, themes and patterns were notated. These coded categories collapse and expand within the constant comparison method (Silverman 2001). The data were analyzed within and between transcripts and linked to the coding categories to ensure that multiple, repeated passes were made of the coded data, which creates a high level of researcher familiarity and confidence in the data to ensure validity and accuracy (Taylor 2001). A systematic investigation is critical to ensure rigor within an analytic analysis, such as a discourse analysis. This flexible and adaptable coding approach allowed for patterns to develop and disappear throughout the process, which resulted in the emergence of the dominant discourses from within the data as a whole (Wiggins and Potter 2007).

The use of more structured coding to support content analysis also allowed for an iterative approach to cross-validation and yielded high internal validity (Taylor 2001). Specifically, patterns of variability (both consistent and inconsistent), emergent themes, nuance, contradiction, and repetition were discovered (Wildemuth 2016). The structured content analysis exposed the general themes of what was said and was complemented by the discourse analysis, which reveals patterns and themes on how interviewees said it (Gergen and Gergen 2004).

The dominant discourses are presented in this study alongside the findings of the content analysis in a narrative form to enable the nuances, relationships, and conflicts to be exemplified, with representational quotations provided to add depth to the findings as generated from the dataset as a whole. Where representative quotations are used, the identity of the interviewee concerned has been 
fully anonymized, as required by the human subject protocol and wider ethical best practices, and follows a format consistent with other empirical qualitative data studies, such as the study by Sherratt et al. (2018).

\section{Results}

\section{Salient Work Attributes}

Throughout the analysis of the transcriptions, coding categories were created based on the responses from participants and were developed, enlarged, reduced, or updated to capture the findings from the data as a whole. Content analysis was undertaken through the early coding stages, and the findings can be seen in Table 3. Many of the findings were aligned with Herzberg's motivator- hygiene model. Management, relationships with peers, work conditions, and pay were all considered to be hygiene factors in Herzberg's model, and achievement, recognition, the work itself, and autonomy/responsibility were motivators (Herzberg et al. 1959). The main point of difference was that tangible results are unique to the construction industry as not all industries produce a significant physical end product, such as a building.

[Table 3 at end of document]

More detailed coding enabled the illumination of the dominant discourses from within the data, and these were further classified as either positive or negative, with the most dominant discourses indicating the following:

- Workers genuinely enjoy their jobs in construction and take pride in their work.

- Workers do not enjoy working with others who do not care about or take pride in their job.

- Workers enjoy social interactions with like-minded coworkers.

- Workers enjoy working with their hands and seeing the tangible results of their efforts.

- Dysfunction or lack of coordination, particularly related to scheduling, from upper management was a ubiquitous negative attribute. 
Although these discourses were consistent throughout the data, there were some inconsistencies among individual attributes, which were considered to be outliers. For example, some of the workers preferred more challenging work tasks that were physically demanding, while others preferred lower mentally and physically demanding jobs. Due to these inconsistencies, the findings in this study represent the dominant discourses, but as proscribed in this methodological approach, they should not be considered the consensus.

Although work conditions can be optimized by understanding and recognizing more desirable work attributes, these attributes are not universal, and the nuance and insight provided by the discourse analysis are therefore explored in more depth in the following sections. The quoted material from the participants in the following subsections was pulled from the report (Sherratt et al. 2018).

\section{Positive Attributes}

Generally, construction workers spoke positively about their jobs. In fact, over $24 \%$ of respondents used the word love to describe their feelings about their work. Construction workers enjoy their jobs and have a high degree of pride in their work. The shared understanding that "you either like what you do, or you don't stay long" was pervasive. It can be challenging, hard work, but ultimately, many of those in the industry have chosen this path, whether from a family trade or for a specific reason, such as the pay or skill. The specific attributes most dominant in the discourse regarding construction work are outlined subsequently.

\section{Tangible Results}

The most dominant discourse throughout the data surrounded the tangible nature of construction work, which creates an enjoyable consequence of labor and something to look forward to, either through individual work, the outputs of their trade, or completion of the project as a whole. "The building itself" is something associated with pleasure and enjoyment, which is part of the construction process, as well as "taking something from the ground and just building entire buildings." This provides “the ability to look back and say, 'I built that' and see [one's] own personal accomplishments." Workers are proud of their craft, and when a project is complete, there is a strong 
individual sense of personal accomplishment. The pride found in construction work also extended to worker's families, with comments such as the following: "I love what I do. I like working hard. I can leave and come back and show my kids what I did one day." As construction is highly reliant on skilled trades, recognizing the tangible, completed project as something that workers most enjoy about their jobs is unique to this industry. Simply being able to say, "I built that today. That wouldn't be there if I didn't do it," is something that makes the construction industry inimitable.

\section{People and Coworkers}

After tangible results, the second most prominent discourse involved their coworkers and the enjoyment found in working alongside others. Workers are friendly, and "people are more personable on a job site than if you're walking down the street." The construction worker was constructed as an amicable person, which in turn closely aligned to the inherently cooperative nature of the work itself and, thus, the need for teamwork for those involved. "It's almost a sportive aspect where you have your team, you set some goals, and then you complete." This extended to the understanding that coworkers were almost like family: "the team aspect—kind of a family—because you spend more time with these guys than you are with your own family a lot of the time." The relatively diverse nature of the workforce was also an aspect of consideration and often positioned positively, with different people with different backgrounds able to offer their individual knowledge to share: "being able to pass around knowledge is cool; you can learn something from any one of these people out here."

However, much of the positivity regarding coworkers relates to the other workers found out in the field and not the site or project management. Although working with other people is one of the more desirable traits, supervisory staff and management were not included in this understanding. Consistent with the literature, the importance of the interpersonal aspects of work is emphasized, and it is notable how drastically they influence the nature of the work and the employment relationships. This social domain of construction work is interesting and arguably one of the least understood of the attributes but has a major influence on the efficiency and effectiveness of the organization (Wilson et al. 2004). 


\section{Challenge/Cognitive Demand}

Interestingly, cognitively demanding and challenging jobs were also positioned as positive work traits. People like demanding and technical work that requires them to learn new things throughout their careers. Problem-solving and troubleshooting was a good thing: "all the problem solving and working with engineers that goes into making things happen — it is rewarding." Despite the perceived physical nature of the work, a discourse of mental challenges could also be identified and is welcomed by the workforce as they enjoyed learning and "getting to use [their] brain." "Learning new things every day :: : learn to know how things are getting done-what the process is" are all aspects of this discourse. Additional considerations include the desire to continue to be trained on more advanced skills, and others noted that they selected their specific trade because it offered the most complex jobs, which they find the most rewarding.

\section{Working with Your Hands}

Perhaps unsurprisingly, there was a common appreciation and enjoyment of jobs that involve working with their hands instead of behind a desk or in an office. A very common trope was that people "like being able to use [their] hands, work hard, and get stuff done." It was noted that the jobs held in construction teach practical skills, which is "something that can actually be applied to life," and there is a clear shared understanding that working with your hands is rewarding. Learning how to use tools and getting dirty by working directly with their hands was even positioned as one of the reasons to join the industry.

\section{Diversity of Work Tasks}

The diversity of work tasks can be associated with the fact that "every day is different" and that workers like the lack of repetitive work. One respondent summed this up well when he said, "I like that we're always doing different things, so you never really get sick of anything — even if you're only doing it for a couple of weeks, and then you move onto something else." Some of the variety in construction is not only related to specific tasks but the location of the project and the project types: "you see different things every day because projects are always changing." This constant change and variety of the job keep construction workers busy, which is desirable to most respondents. 


\section{Movement and Being Outside}

In line with job sites that are constantly changing, it is not surprising that another positive work attribute for many construction workers is the fact that they are not "cooped up inside all the time" and are able to work outside and even travel some for jobs. The desire to work outside far outweighs the alternative, considered to be an indoor desk job. Keeping active and healthy are also very desirable attributes for the work and make the job more enjoyable overall. Again, compared to a desk job, one respondent noted that he does not "worry about [getting overweight], but a lot of people have health problems because they are in an inside field."

\section{Autonomy}

A further understanding among the workers is revealed through a discourse of autonomy: when management is not "breathing down their neck," workers are able to be efficient and productive and enjoy their jobs. Autonomy can be granted because workers are trusted to perform tasks well and because supervisors tend to give freedom to workers to make their own decisions. This association with trust is implicit and often developed from a "combination of knowing what [they are] doing and knowing how to do it in the correct processes." Setting their own pace to complete tasks and even being able to drive the schedule with a quality autonomous crew are considered desirable traits that are found in the construction industry.

\section{Pay}

Adequate pay is a primary reason for entering the industry, closely associated with the notion of entering the family trade. Some workers left their previous careers, or originally chose construction, based solely on the pay. Different trades make more money than others, and workers often chose a trade knowing it pays more than alternate trades might. While it was addressed that the pay could improve, the dominant discourse was that workers are paid enough for what they do. In fact, one respondent explained that he does not believe the construction industry is advertised properly regarding the opportunities with pay: “I didn't know I could get a well-paying job to support a big family." 


\section{Hard Work}

Consistent with the desire for challenging tasks offering high cognitive demand requirements, hard work was a dominant positive trait of construction work. People often stated that they enjoy working hard - in both physically demanding and cognitively demanding jobs. The day-to-day challenges are exciting and desirable to keep construction jobs interesting. This discourse contained a clear negative facet, through which the workers share strong negative feelings around desk jobs and prefer more physically challenging jobs requiring time on their feet and working with their hands-all consistent with hard work.

\section{Pride and Ownership}

Pride and ownership were a dominant discourse with substantial significance as these are unique factors to the construction industry. While only $9 \%$ of the respondents discussed pride in their work specifically, a more nuanced discourse also emerged regarding pride, as participants discussed the importance of caring about their own work but also working with others that also care. The words pride and care were some of the most prominent throughout the discussions as they were linked to other attributes, particularly tangible results. This is unique to the industry as workers expressed pride in the tangible work they produce and the ability to point out projects they have been a part of to their friends and family. The importance of appreciating their own work as well as other's work was expressly essential to the satisfaction of the workers. One respondent referenced a quote from his father, who also worked in construction: "If you work on anything like it's your own, then you have no problem." It was discussed that taking pride in your work produces quality work, which is important in skilled trades, such as construction work.

\section{Negative Attributes}

While the general findings from these interviews were that people enjoyed their careers in the construction industry, when asked to think about negative attributes of construction, workers were able to describe a variety of attributes that they find undesirable about their jobs. Interestingly, workers with more experience often reminisced about the past and expressed their displeasure that construction has changed over the years. They specifically note that projects are being built faster and 
cheaper, and construction has "lost the fun." Aligning with Herzberg's hygiene-motivator theory, factors that were considered to be negative attributes were primarily out of the workers' control.

\section{People and Coworkers}

In a companion discourse to that discussed previously, there were also negative attributes related to social interaction and working with other people on sites. Although the interaction was positive in some contexts, personality conflicts, language barriers, communication issues, lack of pride or respect, temporary labor concerns, lack of knowledge and ambition with newer/younger workforce, workforce shortage, and not enough ownership in work were all positioned as negative aspects of the job. Much of this list can be summarized by an overarching discourse: that construction workers do not like working with other people who do not care about their job or do not take pride in what they do. The phrase "people who don't care" was a prominent trope in describing negative attributes. People work in silos and only pay attention to their work without being proactive about the next trade on the schedule; this lack of awareness of the overall project can create problems between trades.

A connection between hiring issues and personnel issues, a major negative aspect associated with people, was that people hired into construction were not tested and screened properly for adequate skills. Workers explained that with the construction industry booming in this market, there is a need for more labor in the industry. However, this has led to hiring unqualified candidates, which is frustrating for those that consider construction jobs to be a true craft or trade; they are being paid similarly to someone who does not produce the same quality of work, solely due to the workforce shortage. Hiring bodies to fill positions without proper qualifications can backfire on companies as one worker explained: "they're just winging it, and then [we have] to fix all their stuff. So not only [is the company] losing the money they're paying them, they're losing the money that we have to go back and take the time and fix it." There is a loss of the craft of construction due to the "lack of knowledge and ambition that people coming into the trades have nowadays" and the growing need to fill positions. As properly summarized, "everybody wants everything cheaper and faster nowadays so it's taken the fun, and it's taken a lot of the craftsmanship out of the trades." 
It is important to note that coworker interaction was found to be a divergent discourse (both positive and negative). People enjoy working around a diverse group of friendly, hardworking individuals in the field with the ability to learn valuable information from each other. On the other hand, over a third of participants felt that the other spectrum of people in construction that do not care about their work cause social interaction actually to be a negative dimension of their job.

With coworkers and social interaction being a divergent dimension, it is important to determine which aspects should be preserved and which should be avoided to promote an improvement in the field. Likely, this differentiation stems from the hiring process when many of the participants noted that problems begin. The bottom line with regards to people in construction is that those who enjoy their jobs and are proud of their work are also frustrated by workers who do not care about their work. With known workforce shortage challenges in construction, the participants noted that organizations seem to be hiring simply to fill positions without proper screening and training on required skills or motivation for the work. As the main positive feedback related to coworkers was working alongside other hard-working, positive individuals, there could be the possibility for improving overall job satisfaction by ensuring that workers in construction are screened and trained properly.

\section{Scheduling and Coordination}

The category of scheduling and coordination encompasses logistical challenges, coordination issues at the project and trade levels, lack of foresight and planning, long working hours, and specific scheduling concerns. Nearly all construction workers agree that scheduling challenges have evolved, and project schedules are more condensed. For example, workers noted that "we all want it to slow down. Years ago, you had time to do your job right. Now you have to do your job right and fast." The participants feel that more time needs to be scheduled into jobs as the rush of projects can cause issues.

In fact, one worker explained that the problem appears to be cyclical: "Schedules keep getting tighter and tighter because we in the field make it happen. And if we make that tight schedule happen, then the [project managers] are going to push the bar a little bit higher" and keep pushing the schedules. 
Construction workers feel that the schedules they are expected to adhere to are not realistic and are created by those who are not in the field, so they do not fully understand the construction project.

Additionally, the need for proper coordination among trades is critical to keep projects moving smoothly, but it was discussed as one of the major concerns on job sites. Trades tend to be scheduled to work in the same areas where the overlapping work causes issues for the workers. Finally, the red tape required to make decisions and changes can be a conflict as well—workers do not feel empowered to make decisions in the field without going through the extensive, time-consuming channels that often slow the work down significantly.

\section{Communication}

Scheduling and coordination were often cited as a symptom of poor communication. Although communication issues include language barriers and top-down corporate communications, participants more commonly believe that information is being lost or not disseminated properly among trades, and there are deficiencies related to spatial and logistical coordination. A representative comment was that "things slip through the cracks and people get lazy in how they communicate things to other people, and subsequently, things get lost." Additionally, there appears to be a significant disconnect between upper management and the field. Office politics, bureaucracy, and a perceived disconnect with corporate leadership were all issues, summarized as follows: "The organization is a big thing $::$ : if the upper management is organized, then it makes everybody else's job easier."

\section{Upper Management}

Pressure from upper management was a significantly discussed negative work dimension. In line with the desire for autonomy, one worker stated that companies should "let the workers work and the management stay the management." A general dysfunction with regards to management was described by the respondents, and this disorganization makes the jobs of the workers in the field more challenging. Added, unnecessary pressure from above caused stress and issues for the workers. Additionally, overmanaging or micromanagement was positioned as a negative work attribute. 
Finally, workers feel that upper management is too separated from the field, and they are too disconnected from the actual work to be successful. This same issue causes problems with sharing critical information or even the recognition of strong work.

\section{Weather and Site Conditions}

Although often out of the control of any project team, issues with the weather were addressed by $14 \%$ of the participants. Undesirable working conditions were associated with working outdoors, such as extreme weather conditions, heat, and cold. Interestingly, even though the extreme conditions are undesirable, the opportunity to be outside during the workday was generally considered a positive work attribute, adding another facet to this discourse. Site mobility was also discussed in regards to time spent waiting for skips or elevators to travel multiple floors on a project.

\section{Health and Safety}

Negative attributes associated with health and safety included those related to specific work tasks that were more dangerous or ergonomically challenging (e.g., working on knees or ladders and heavy lifting). Specific tasks, such as working on the roof or underground, were cited as examples of work that is "tough on your body," and being around dust was described as an attribute that is disliked. There was also a heavy focus on safety as a negative attribute in construction. Although workers believe safety is important, they also felt the industry's regulatory-based approach to safety was overbearing and counterproductive. Participants generally noted that there were inconsistencies with safety within their company and across the industry. As one worker noted, "every job site is different" when it comes to safety requirements, and construction workers find this inconsistency to be a disadvantage. Even more interesting, some participants stated that while an emphasis on safety is desired, it is being pushed too far with management in following "the book more than common sense."

\section{Comparison to Existing Literature}

Additionally, the findings from this study were cross-referenced with findings from previous prevailing research, as discussed in the literature review and shown in Table 4 . While there was 
substantial alignment with work attributes from other industries, such as human interaction, the work itself, and responsibility, there were some positive and negative attributes identified that were unique to the construction industry. Four positive attributes were added for construction: (1) movement and exercise, (2) building with hands, (3) problem solving, and (4) easy work tasks. At the same time, two negative attributes were added: (1) health and safety; and (2) logistics, planning, and coordination. While there may be some overlap between attributes, such as problem-solving, challenges, or the work itself, some of these attributes that were added are likely due to the unique nature of construction work. These added attributes are valuable when seeking to understand what unique attributes of construction work can be used to improve the industry, while alignment with existing work attributes aids in building upon the existing knowledge of work preferences as studied in social sciences by examining its generalizability to construction.

The most desirable attributes of work in construction were tangible results, cognitive demand, and positive coworker interaction. While cognitive demand, in varying forms, and human interaction or team dynamics are positive work attributes across many other studies, the concept of tangible results is unique to the construction industry. Over half (53\%) of respondents in this study discussed tangible results as what they liked most about their jobs, which is not a common attribute discussed by workers in other industries. Along with the negative attributes, poor coworker interactions, issues with scheduling, and logistical and coordination issues were the most discussed. Coworker issues seem to span all industries, but scheduling and complex coordination issues appear to be more prevalent in the construction industry, likely due to the nature of the work on active job sites as compared to an office setting. These findings align with Herzberg's motivator-hygiene model that forms the bedrock of motivational practice. Ultimately, his model showed that there are two types of factors that an organization can adjust to influence motivation in the workplace: the motivators (positive attributes) encourage harder work while hygiene factors (negative attributes) will not encourage harder work but will cause a decrease in motivation if present.

Following Herzberg's motivator-hygiene model, the following steps should be used to implement the findings of this construction- focused research: 
1. Firstly, the removal of any negative attributes that cause dissatisfaction should be undertaken, such as altering bureaucratic company policies, ensuring team members feel supported and not micromanaged, ensuring that pay is competitive in the field, and constructing jobs or tasks to ensure workers feel their jobs are meaningful.

2. Secondly, job satisfaction should be improved by improving the actual job role itself and empowering workers.

Herzberg's model has faced some criticism, such as its application to only white-collar workers, not taking the specific aspects of individuals into consideration (i.e., creating generalizations), and its focus on employee satisfaction rather than the proxy of productivity. However, the positive and negative attributes found in construction were found to broadly align with Herzberg's theory, which can be interpreted to suggest that his findings can also be applied to blue-collar workers, such as construction industry trades. Furthermore, previous studies have found that improving job satisfaction can actually improve worker productivity (Aletraris 2010). This knowledge can enable humancentered decisions that positively impact construction worker well-being and possibly impact recruitment and retention strategies.

\section{Implications}

There are many practical applications of the results of this study, including improving recruitment strategies, retention tactics, organization management, and change management in construction. These are only some of the opportunities for application as revealed by our empirical work undertaken thus far-although they do provide insights and suggestions that professionals can use as the foundations of their own initiatives and practice. Further research on work dimensions in construction will continue to contribute to the overall body of knowledge, enabling additional applications ranging from field personnel to upper management, and support the development of more action-oriented and practical findings in due course.

[Table 4 at end of document] 


\section{Recruitment}

Practitioners may use the results of this work in future efforts to bring young workers into the industry and keep them engaged for a fulfilling career. Current recruitment includes more general strategies not specific to the construction industry, such as forward planning, clean job descriptions, advertising properly, and intern- ships and apprenticeships. Using the general strategies currently available but enhanced with construction-specific research has the potential to create stronger connections for bringing young people into the industry. The findings from this study provide additional tools to encourage young people to consider an early job in construction.

This research shows that many of the people that remain in construction for their full career feel proud of their work, challenged, motivated, and overall satisfaction with their jobs. Many choose this industry, while there is a misconception that most people just end up in construction due to reasons outside their control. Some participants in this study even mentioned joining the industry due to the high-paying jobs available and the consistent work. Defining a clear path upwards for future construction candidates with research showing that construction is not a "last resort" type of job is important. Some of the main highlights of positive work attributes in construction are likely in line with what many young people are looking for in a career, such as autonomy, diversity of work tasks, and a positive environment with coworkers.

\section{Retention}

The analysis in this study provided insight that there are some issues with the younger generation not caring about their work in the same way the long-term construction workers do. Vetting new employees and providing adequate and thorough training, possibly through apprenticeships and internships prior to or during college, could possibly alleviate these issues. Delving further into the scheduling and communication issues, particularly with keeping upper management from affecting the coveted autonomy of construction work, and mitigating some of the health and safety concerns (ideally removing more of the red tape issues), could have a positive effect on retention as well. People have left the construction industry for some of the reasons found in this study, and younger workers often mentioned that they were only working construction as a part-time job while pursuing 
something they felt would offer more in the long run. Construction was found to be attractive, and those who have worked in the industry for decades have stayed, even when given the opportunity to leave.

\section{Organization Management}

Applying these findings to organization management through possibilities, such as workplace design, the structuring of teams, assessing worker hours and involvement, and changes to communication, could improve the construction industry from the inside out. Improving channels of communication and reducing red tape could positively affect the work experience. Working to improve scheduling conflicts or increasing buy-in from subcontractors on schedules could reduce some of the issues described by the participants in this study. There was an evident discord between those building the schedules in construction and those putting the work in place. Additionally, working to improve the hiring process by requiring a practical skills exam, thoroughly screening new hires, and offering more robust training programs for new hires would reduce the issues related to negative social interactions.

\section{Management of Change}

Through a strategic design and implementation of technology, positive attributes of the work can be promoted, and negative attributes can be mitigated. For example, more involvement in the workforce implementation of change could increase buy-in and feelings of involvement and autonomy. This could improve job satisfaction and motivation, which likely would positively affect employee retention. Understanding the attributes of construction that are more desired and those that are less desired is information that can be applied across a variety of uses, from technology implementation to changes in organizational structure or culture. Strategy with thought given to these attributes may improve overall worker well-being, productivity, safety, and quality. Such improvement may, in turn, improve the success of the entire industry.

\section{Limitations}

There are several limitations of this work related to the data collection method and analytical technique. Our sample only included participants working on commercial sites in Colorado, which 
limits the ability to generalize the findings across the construction industry as a whole. Cross-cultural differences across the world make it difficult to generalize the findings beyond Caucasian and Hispanic workers who have been captured in this data set, but future studies should seek to explore variability across cultures in the construction industry context. Furthermore, although a social constructionist approach cannot draw on traditional positivistic measures that provide internal validity, such as controlled testing environments, the external and ecological validity of this data is high because the data comes directly from the targeted population, demographical variability was captured within this group, and there was a saturation of information within the data collected.

Additionally, there is some opposition to using software programs to aid discourse analysis, but this method was used to develop direction (Seidel 1991) and separate the researchers from pre-existing biases (Barry 1998; Hinchliffe et al. 1997).

There is a level of subjectivity with social science data analysis, such as that used in this study. A social constructionist approach often faces challenges around issues of the interpretation of data and bias; however, in this study, this concern has been mitigated by combining both discourse analysis and content analysis. Within-method triangulation is the use of two or more different methods from within a particular methodological approach to measure the same phenomenon (Harbers and Neerincx 2014). Often, with interview-type data collection, there can be some concerns that participants will not answer openly and honestly. In this case, the anonymity of the process as well as the environment established by the interview approach used, and the ability to opt-out of the interview led to very detailed and thoughtful responses.

\section{Conclusion}

It is important to understand the preferences of construction workers to ensure that positive attributes for the job are preserved while negative attributes are avoided or mitigated. By employing a social constructionist approach to conduct interviews with construction workers on site, the richness of the discussion was preserved as the differing discourses emerged from the data. These findings indicated that most workers enjoy task variety, challenging work tasks, seeing tangible and immediate results, social interaction, movement and exercise, autonomy, and working with their hands. Conversely, the 
attributes most discussed negatively were scheduling, logistics, coordination, communication with upper management, and people who do not take pride in their work. These findings can be used to improve recruitment and retention strategies while also being applied to organization management and change management. Such consideration may increase the likelihood and enthusiasm of adoption and help with retaining human resources.

The information presented in this study could be further investigated or used to provide change and technological implementation guidelines, with a focus on maintaining high levels of job satisfaction and motivation. Additionally, this method could be applied before and after a change is implemented in construction, such as a change to safety regulations.

Continuing the efforts to shift the focus in construction research to human resources will provide a useful set of information that is as dynamic and unique as the actual human beings in the workplace. Continuing to evolve this research with more detailed demographic studies and analysis of the applications on practical ideas, such as recruitment, retention, and change management, could provide additional insight to benefit the workforce issues in the construction industry. The information from this study can also be used to adjust and improve recruitment strategies for younger generations, and the improvement could be statistically measured to determine its effectiveness.

\section{Data Availability Statement}

Some or all data, models, or code that support the findings of this study are available from the corresponding author upon reasonable request.

\section{References}

Aletraris, L. 2010. "How satisfied are they and why? A study of job satisfaction, job rewards, gender and temporary agency workers in Australia." Human Relat. 63 (8): 1129-1155. https://doi.org/10.1177/0018726709354131.

Amabile, T. M. 1997. "Motivating creativity in organizations: On doing what you love and loving what you do." Calif. Manage. Rev. 40 (1): 39-58. https://doi.org/10.2307/41165921. 
Barry, C. A. 1998. "Choosing qualitative data analysis software: Atlas/ti and Nudist compared." Sociol. Res. Online 3 (3): 16-28. https://doi.org/10.5153/sro.178.

Beer, M., P. R. Laurence, Q. N. Mills, and R. E. Walton. 1985 Human resource management. New York: Free Press.

Bowen, B. E. 1980. "Job satisfaction of teacher educators in agriculture.” Unpublished doctoral dissertation, Dept. of Agricultural Education, Ohio State Univ.

Burck, C. 2005. "Comparing qualitative research methodologies for systemic research: The use of grounded theory, discourse analysis and narrative analysis.” J. Family Ther. 27 (3): 237-262. https://doi.org/10.1111/j.1467-6427.2005.00314.x.

Bureau of Labor Statistics. 2019. Labor force statistics from the current population. Washington, DC: Bureau of Labor Statistics.

Burr, V. 2003. Social constructionism. London: Routledge.

Cohen, D. J., and L. Prusak. 2001. "In good company: How social capital makes organizations work.” Ubiquity 2001 (Jan). https://doi.org/10.1145/358974.358979.

Construction Industry Resources. 2017. Estimates developed. Lexington, KY: Construction Industry Resources.

Csikszentmihalyi, M. 2000. Beyond boredom and anxiety. San Francisco: Jossey-Bass Publishers.

Druker, J., G. White, A. Hegewisch, and L. Mayne. 1996. "Between hard and soft HRM: Human resource management in the construction industry." Constr. Manage. Econ. 14 (5): 405-416. https://doi.org/10.1080/014461996373278.

Edmonds, J. 2016. "What is human factors?" In Human factors in the chemical and process industries, 3-11. Amsterdam, Netherlands: Elsevier. 
Eggert, R., A. Joshi, S. Mehrotra, Y. V. Zastavker, and V. Darer. 2014. "Using discourse analysis to understand 'failure modes' of undergraduate engineering teams." In Proc., Frontiers in Education Conf. New York: IEEE.

Estridge, L. K. 2018. “What makes people love their jobs?” Accessed September 1, 2018. https://careerpotential.com/career-advice-article/makes-people-love-jobs/.

Gergen, K. J., and M. Gergen. 2004. Social construction: Entering the dialogue. Chagrin Falls, OH: Taos Institute Publication.

Goodrum, P. M. 2004. "Hispanic and non-Hispanic wage differentials: Implications for United States construction industry.” J. Constr. Eng. Manage. 130 (4): 552-559. https://doi.org/10.1061/(ASCE)0733-9364(2004)130:4(552).

Haas, C. T., A. M. Rodriguez, R. Glover, and P. M. Goodrum. 2001. "Implementing a multiskilled workforce.” Constr. Manage. Econ. 19 (6): 633-641. https://doi.org/10.1080/01446190110050936. Harbers M., and M. A. Neerincx. 2014. "Value sensitive design of automated workload distribution support for traffic control teams.” In Vol. 8532 of Engineering psychology and cognitive ergonomics, Lecture notes in computer science, edited by D. Harris. Cham, Switzerland: Springer. https://doi.org/10.1007/978-3-319-07515-0_2.

Herzberg, F., B. Mausner, and B. B. Snyderman. 1959. The motivation to work. New York: Wiley. Hinchliffe, S. J., M. A. Crang, S. M. Reimer, and A. C. Hudson. 1997. "Software for qualitative research: 2. Some thought on 'aiding' analysis.” Environ. Plann. 29 (1): 1109-1124. https://doi.org/10.1068/a291109.

Hinkin, T. R., and J. B. Tracey. 2000. "The cost of turnover: Putting a price on the learning curve." Cornell Hotel Restaurant Admin. Q. 41 (3): 14-21.

Jørgensen, M., and L. Phillips. 2011. Discourse analysis as theory and method. Los Angeles, CA: SAGE. 
Karimi, H., T. R. B. Taylor, P. M. Goodrum, and C. Srinivasan. 2016. "Quantitative analysis of the impact of craft worker availability on construction project safety performance.” Constr. Innovation 16 (3): 307-322. https://doi.org/10.1108/CI-10-2015-0050.

Kosteas, V. D. 2010. “Job satisfaction and promotions.” J. Econ. Soc. 50 (1): 174-194. https://doi.org/10.1111/j.1468-232X.2010.00630.x.

Kumar, R. 2005. Research methodology. London: SAGE.

Lobo, Y. B., and S. Wilkinson. 2008. "New approaches to solving the skills shortages in the New Zealand construction industry.” Eng. Constr. Archit. Manage. 15 (1): 42-53. https://doi.org/10.1108/09699980810842052.

Locke, E. A. 1969. “What is job satisfaction?” Organizational Behav. Human Perform. 4 (4): 309336. https://doi.org/10.1016/0030-5073(69)90013-0.

Makhene, D., and W. D. Thwala. 2009. "Skilled labour shortages in construction contractors: A literature review.” In Proc., CIDB 6th Post Graduate Conf, 128-136. Johannesburg, South Africa: CIDB.

Padilla-Velez, D. 1993. "Job satisfaction of vocational teachers in Puerto Rico.” Unpublished doctoral dissertation, Dept. of Agricultural Education, Ohio State Univ.

Paltridge, B. 2013. Discourse analysis: An introduction. London: Bloomsbury.

Potter, J., and A. Hepburn. 2008. Discursive constructionism. In Handbook of constructionist research, 275-293. New York: Guilford Press.

Seidel, J. 1991. "Methods and madness in the application of computer technology to qualitative data analysis.” In Using computers in qualitative research, 107-116. London: SAGE.

Seijts, G. H., and D. Crim. 2006. "What engages employees the most or, the ten C's of employee engagement.” Ivey Bus. J. 70 (4): 1-5. 
Shelar, S. 2013. "141 ideas for solving the construction industry's labor shortage.” Accessed April 9, 2014. http://constructioncitizen.com/blog/141-ideas-solving-construction-industrys-laborshortage/1312271?goback=\%2Egde_4972139_member_5823510803969486850\#\%21.

Sherratt, F., K. Welfare, M. Hallowell, and M. Hoque Tania. 2018. "Legalized recreational marijuana: Safety, ethical, and legal perceptions of the workforce.” J. Constr. Eng. Manage. 144 (6): 04018048. https://doi.org/10.1061/(ASCE)CO.1943-7862.0001502.

Silverman, D. 2001. Interpreting qualitative data: Methods for analysing talk, text and interaction, 2nd ed. London: SAGE.

Taylor, S. 2001. "Locating and conducting discourse analytic research." In Discourse as data: A guide for analysis, 5-48. London: SAGE. Turner, A. N., and P. R. Lawrence. 1965. Industrial jobs and the worker.

Boston: Harvard University Graduate School of Business Administration. Walton, R. E. 1985. From control to commitment in the workplace: In factory after factory, there is a revolution under way in the management of work. Washington, DC: US Dept. of Labor, Bureau of Labor-Management Relations and Cooperative Programs.

Wetherell, M., and J. Potter. 1988. "Discourse analysis and the identification of interpretative repertoires.” In Analysing everyday explanation: A casebook of methods. Thousand Oaks, CA: SAGE.

Wiggins, S., and J. Potter. 2007. "Discursive psychology." In The sage handbook of qualitative research in psychology. London: SAGE. Wildemuth, B. M. 2016. Applications of social research methods to questions in information and library science. 2nd ed. Santa Barbara, CA: ABC-CLIO. Wilson, M. G., D. M. Dejoy, R. J. Vandenberg, H. A. Richardson, and A. L. Mcgrath. 2004. "Work characteristics and employee health and well-being: Test of a model of healthy work organization." J. Occup. Organ. Psychol. 77 (4): 565-588. https://doi.org/10.1348/09631790 42596522. 


\section{Tables}

Table 1. Work attributes from literature

\begin{tabular}{|c|c|c|c|c|c|c|c|c|}
\hline \multirow{3}{*}{ 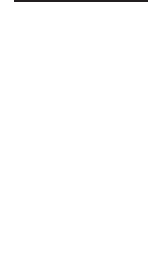 } & Herzber & Turner & & & Hinki & Coh & Seijts & \\
\hline & get al. & Lawrenc & Amabi & Csikszentmih & $\mathrm{n}$ & en & and & Estrid \\
\hline & & $\mathrm{e}$ & le & alyi & Trac & Prusa & Crim & ge \\
\hline \multirow{3}{*}{ Source } & \multirow{3}{*}{ (1959) } & & \multirow{3}{*}{ (1997) } & \multirow{3}{*}{ (2000) } & ey & $\mathrm{k}$ & & \\
\hline & & (196 & & & (200 & $(200$ & (200 & (201 \\
\hline & & 5) & & & 0) & 1) & 6) & 8) \\
\hline
\end{tabular}

Positive attributes

Human interaction and team dynamics

$\mathrm{X}$

$\mathrm{X}$

$\mathrm{X}$

-

$\mathrm{x}$

$\mathrm{x}$

$\mathrm{x}$

Variety and creativity

Autonomy

$-$

Upper management/communication -

Pay

The work itself

$\mathrm{X}$

$\mathrm{X}$

$-$

-

X

$\mathrm{X}$

Motions and patterns of activity

$\mathrm{x}$

$\mathrm{x} \quad \mathrm{X}$

-

$-$

$-\quad-$

$\mathrm{x}$




\begin{tabular}{|c|c|c|c|c|c|c|c|c|}
\hline Extrinsic competition & - & $\mathrm{x}$ & - & $\mathrm{x}$ & - & - & - & - \\
\hline Intrinsic competition & - & $\mathrm{x}$ & - & $\mathrm{x}$ & - & - & - & - \\
\hline Emotional release & - & $\mathrm{x}$ & - & $\mathrm{x}$ & - & - & - & - \\
\hline Prestige, pride, and glamour & - & - & - & $\mathrm{x}$ & - & - & $\mathrm{x}$ & $\mathrm{x}$ \\
\hline Rewards and recognition & $\mathrm{x}$ & - & 一 & - & - & - & $\mathrm{x}$ & $\mathrm{x}$ \\
\hline Responsibility & $\mathrm{x}$ & $\mathrm{x}$ & - & - & - & - & - & $\mathrm{x}$ \\
\hline Growth and learning & $\mathrm{x}$ & - & - & - & - & - & $\mathrm{x}$ & $\mathrm{x}$ \\
\hline Involvement in change & - & - & - & - & - & - & - & $\mathrm{x}$ \\
\hline Goals and achievement & - & - & $\mathrm{x}$ & - & - & $\mathrm{x}$ & $\mathrm{x}$ & $\mathrm{x}$ \\
\hline Challenge & - & - & $\mathrm{x}$ & - & - & $\mathrm{x}$ & $\mathrm{x}$ & - \\
\hline \multicolumn{9}{|l|}{ Jegative attributes } \\
\hline Policy and administration & $\mathrm{x}$ & - & - & - & - & - & - & - \\
\hline Supervision & $\mathrm{x}$ & - & - & 一 & $\mathrm{x}$ & - & - & - \\
\hline Pay & $\mathrm{x}$ & - & - & - & $\mathrm{x}$ & - & - & - \\
\hline Coworkers & $\mathrm{x}$ & - & - & - & - & - & - & - \\
\hline Work conditions & $\mathrm{x}$ & - & - & - & - & - & - & - \\
\hline
\end{tabular}


Table 2. Demographic profile

\begin{tabular}{lc}
\hline Years of experience & $\begin{array}{c}\text { Number of } \\
\text { participants }\end{array}$ \\
\hline$<1$ & 18 \\
$1-5$ & 59 \\
$6-10$ & 42 \\
$10-20$ & 57 \\
$20 p$ & 46 \\
\hline
\end{tabular}


Table 3. Work attributes by percentages

\begin{tabular}{|c|c|c|c|}
\hline Desired attributes of work & $\begin{array}{l}\text { Percentage of respondents } \\
\text { (\%) }\end{array}$ & Disliked attributes of work & $\begin{array}{l}\text { Percentage of } \\
\text { respondents (\%) }\end{array}$ \\
\hline Tangible results & $\begin{array}{l}5 \\
3\end{array}$ & People & 36 \\
\hline Cognitive demand & $\begin{array}{l}2 \\
2\end{array}$ & Scheduling & 27 \\
\hline People & $\begin{array}{l}1 \\
8\end{array}$ & $\begin{array}{c}\text { Logistics, planning, and } \\
\text { coordination }\end{array}$ & 19 \\
\hline Working with hands & $\begin{array}{l}1 \\
8\end{array}$ & Communication & 18 \\
\hline Diverse tasks - always & 1 & Upper management & 15 \\
\hline changing & 7 & & \\
\hline Movement and being & 1 & Weather and site conditions & 14 \\
\hline outside & 6 & & \\
\hline Autonomy & $\begin{array}{l}1 \\
2\end{array}$ & Safety & 12 \\
\hline
\end{tabular}


Hard work

Problem solving

Detailed work

Stability

Safety

Appreciation and recognition
Drawing errors or rework

0

9

Hours

Pay 8

Heavy lifting 6

Repetition 6

Dirty or hard work 4

Favoritism 4 
Table 4. Work attributes from literature

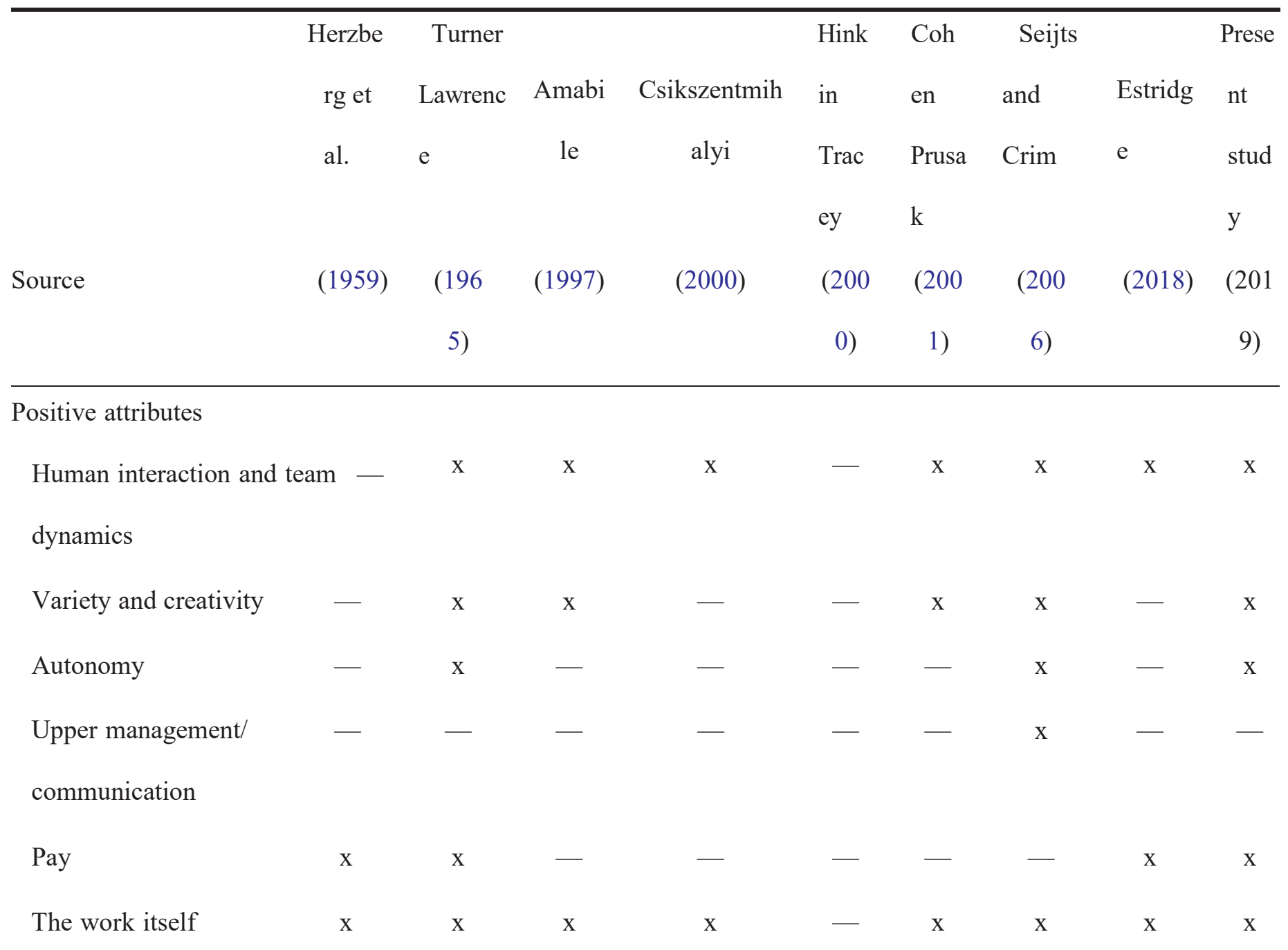


Motions and patterns of

activity

\section{Extrinsic competition}

Intrinsic competition

Emotional release

Prestige, pride, and glamour -

Rewards and recognition $\mathrm{x}$

Responsibility

Growth and learning

Involvement in change

Goals and achievement

Challenge

Movement and exercise

Building with hands

Problem solving

Easy work tasks $\mathrm{x}$

$\mathrm{x}$

$\mathrm{x}$

$\mathrm{X}$

$x$

$-$

$-$

$-$

-

- -

- $\quad \mathrm{x}$

-

-

-

-

-
$\mathrm{X}$

$x$ 
Negative attributes

\begin{tabular}{|c|c|c|c|c|c|c|c|c|}
\hline Policy and administration & $x$ & - & - & - & - & - & - & - \\
\hline Supervision & $\mathrm{x}$ & - & - & - & $\mathrm{x}$ & - & - & - \\
\hline Pay & $\mathrm{x}$ & - & - & - & $\mathrm{x}$ & - & - & - \\
\hline Coworkers & $\mathrm{x}$ & - & - & - & - & - & - & - \\
\hline Work conditions & $\mathrm{x}$ & - & - & - & - & - & - & 一 \\
\hline Health and safety & - & - & - & - & - & - & - & - \\
\hline Logistics, planning, and & - & - & - & - & - & - & - & - \\
\hline
\end{tabular}

coordination 